\title{
A concise operation safety protection device in arm of tower crane and its parameter design
}

\author{
Xiao Lv ${ }^{1, a}$, Lei Zhang ${ }^{1, b}$, Ligui Kang ${ }^{1, c}$, Zhuo Chen ${ }^{1, d}$ and Tonghai Xie ${ }^{2, e}$ \\ ${ }^{1}$ Chongqing Special Equipment Inspection and Research Institute, Chongqing, 401121, China \\ ${ }^{2}$ Chongqing cloud tower machinery manufacturing corporation limited, Chongqing, 404100, China \\ aIvxia087@126.com(corresponding author), ${ }^{b} Z$ L_816@126.com, \\ c50104866@qq.com, ${ }^{\mathrm{d}} 420725690 @ q q . . c o m$
}

Keywords: Tower crane, operation safety protection, parameter design.

\begin{abstract}
In view of the operation safety problem in arm of tower crane, a novel safe belts hanging protection device which has the characteristics of easily removed and high safety is proposed. Based on mechanical theory, constrains of rope diameter, fixed plate thickness, orifice cross section, the bolt size are discussed. Consequently, an integrated design process for parameters of protection device is proposed, and such method can ensure the safety of operating personnel.
\end{abstract}

\section{Introduction}

In the operation and maintenance process, operators needs go along the sweep and go from the root to the front in order to find the potential safety hazard in tower crane. Generally, this work can be done in two ways. First one is to drive the cart in which there is basket that can move with the vehicle. Second is that operators climbs along the sweep to do the work. Practically, safety hazard exists in these two methods. In the first one, due to the unbalanced stress, the basket in the cage can easily break and fall to cause the accident. There are accidents of falling baskets. In the second method, the operators' safety belt is not be fastened. If the belt is fastened, it's inconvenient for the operators to work. Thus in practice, the safety belt is not used which can increase the possibility of accidents significantly. And in practice, cases that workers are threw from the sweep exist. In order to ensure the safety of the operators working in the crane sweep and avoid harm to workers, a safety device convenient for work and belt fastening is proposed. This device can not only fasten the belt but also avoid of decreasing the flexibility of operators.

\section{Structure of novel safety device}

The safety protection device is based on the upper chord of tower crane jib, which is composed of a steel wire rope and wire rope fixing device with a proper strength. The safety belt buckles on the steel wire rope through the fixed buckle so that it can freely slide and protect the operator in the operation process, and its scheme is shown in Fig.1.

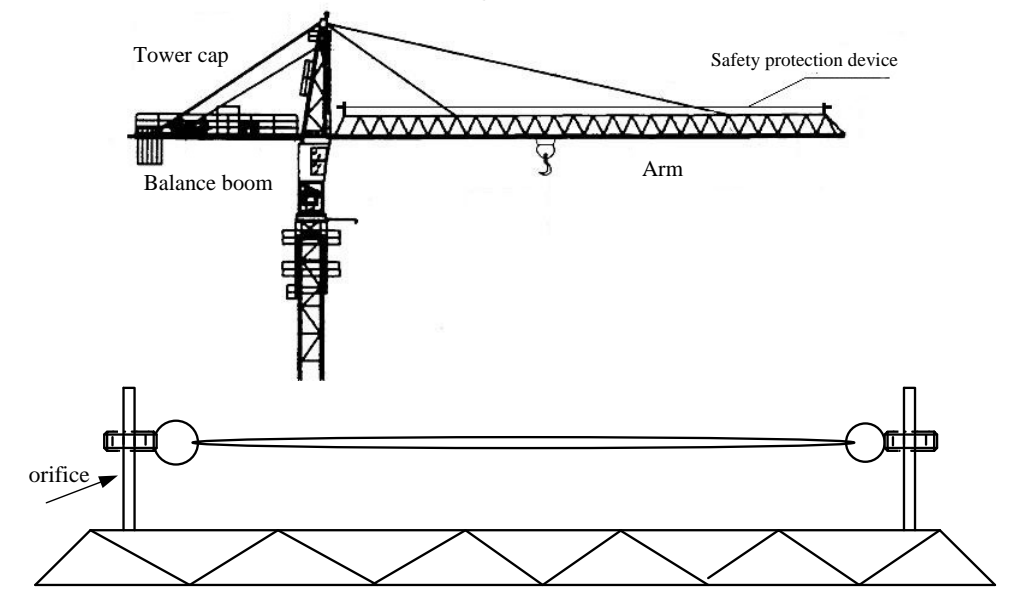

Fig.1 Schematic of tower crane with safety protection device 
As shown in Fig.1, the safety protection device mainly includes wire rope tension bolt, steel wire rope and the orifice. In order to meet the safety requirements, it is necessary to design the parameters of components.

\section{Parameter design}

At first, some variables defined as follows. The weight of human is $\mathrm{W}(\mathrm{kg})$. The thickness of stationary steel plates is $\delta(\mathrm{cm})$. It can be known the dynamic load in a fall of human is $\mathrm{W}_{1}=9.8 \mathrm{~W}$. So the total load is $\mathrm{P}=\mathrm{W}+\mathrm{W}_{1}=10.8 \mathrm{~W}(\mathrm{~kg})$.

\section{Constraint for diameter of steel wire rope}

According to the engineering technical design specification, it can be known that the maximum tensile strength of steel wire rope $\delta_{\text {rope }}$ is $1400(\mathrm{mpa})$. So the diameter of steel wire rope $\mathrm{A}_{\text {rope }}$ can be expressed as

$$
\mathrm{A}_{\text {rope }}>\mathrm{P} / \delta_{\text {rope }}=10.8 \mathrm{~W}(\mathrm{~kg}) / 1400(\mathrm{mpa})=0.0007563 \mathrm{~W} \quad\left(\mathrm{~cm}^{2}\right)
$$

\section{Constraint for thickness of stationary steel plates}

The length of the weld $\mathrm{D}$ is about $100(\mathrm{~mm})$,so the sectional area of stationary steel plates $\mathrm{A}_{\mathrm{p}}=$ $\delta \times 10\left(\mathrm{~cm}^{2}\right)$. There are two sections for bearing the load, so the load of each stationary steel plate $\mathrm{P}_{1}=\mathrm{P} / 2=5.4 \mathrm{~W}(\mathrm{~kg})$. According to the engineering technical design specification, it can be known that the maximum tensile strength of stationary steel plates $\mathrm{Z}$ is $1000\left(\mathrm{~kg} / \mathrm{cm}^{2}\right)$. So the thickness of stationary steel plate $\delta$ can be expressed as

$$
\delta>\mathrm{P}_{1} /(10 \mathrm{Z})=0.00054 \mathrm{~W} \quad(\mathrm{~cm})
$$

\section{Constraint for sectional area of orifice}

As mentioned above, the sectional area of orifice $\mathrm{A}_{\text {or }}$ can be expressed as

$$
\mathrm{A}_{\text {or }}>\mathrm{P}_{1} / \mathrm{Z}=0.0054 \mathrm{~W} \quad\left(\mathrm{~cm}^{2}\right)
$$

\section{Constraint for sectional area of wire rope tension bolt}

According to the engineering technical design specification, it can be known that the maximum tensile strength of wire rope tension bolt $\delta_{\text {ten }}$ is $1700\left(\mathrm{~kg} / \mathrm{cm}^{2}\right)$. So the diameter of steel wire rope $\mathrm{A}_{\text {bolt }}$ can be expressed as

$$
\mathrm{A}_{\text {bolt }}>\mathrm{P}_{1} / \delta_{\text {ten }}=0.003176 \mathrm{~W} \quad\left(\mathrm{~cm}^{2}\right)
$$

\section{Process of parameter design}

The flow chart shown in Fig.2 shows a simplified design methodology for proposed safety protection device such as a calculation sheet. The main parameter in the design is the choice of the above mentioned, and an iterative process is followed that results in the optimum parameter. For a given human weight $\mathrm{W}$ and length of the weld $\mathrm{D}$, the all parameters could be calculated. If some parameter does not fit on the actual production, a different $\mathrm{D}$ must be chosen. 


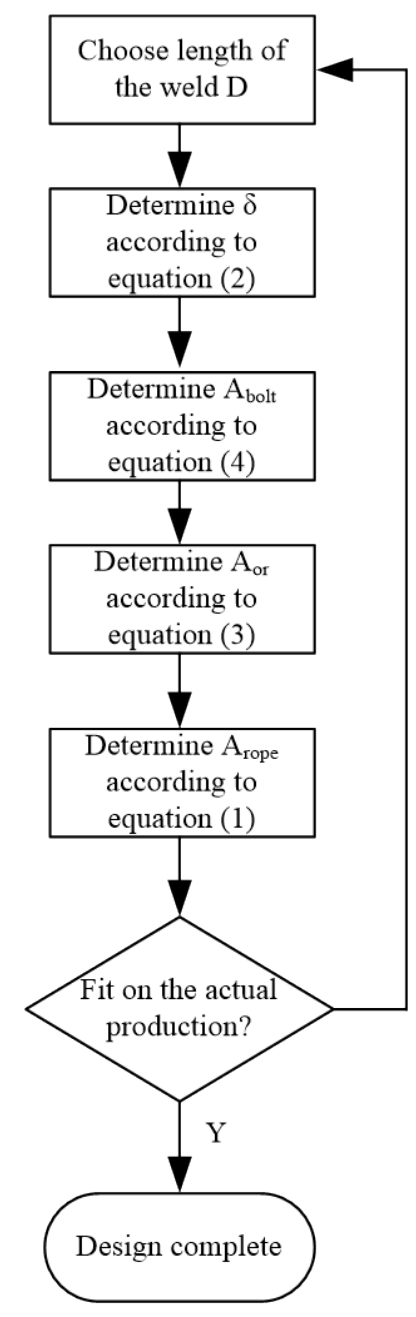

Fig.2 Parameter design flow chart

\section{Simulation}

According to the characteristic of the structure, the simulation and analysis was operated by the simplified two-dimensional model. The model has been used finite element method by ANSYS software for force analyzing. The modulus of elasticity of the metal materials was 2.05GPa, and the poisson ratio was 0.25 . The force applied at the middle of the wire rope was $750 \mathrm{~N}$. The Fig. 3 showed the mechanical strain of the wire rope which could load the weight of a person.
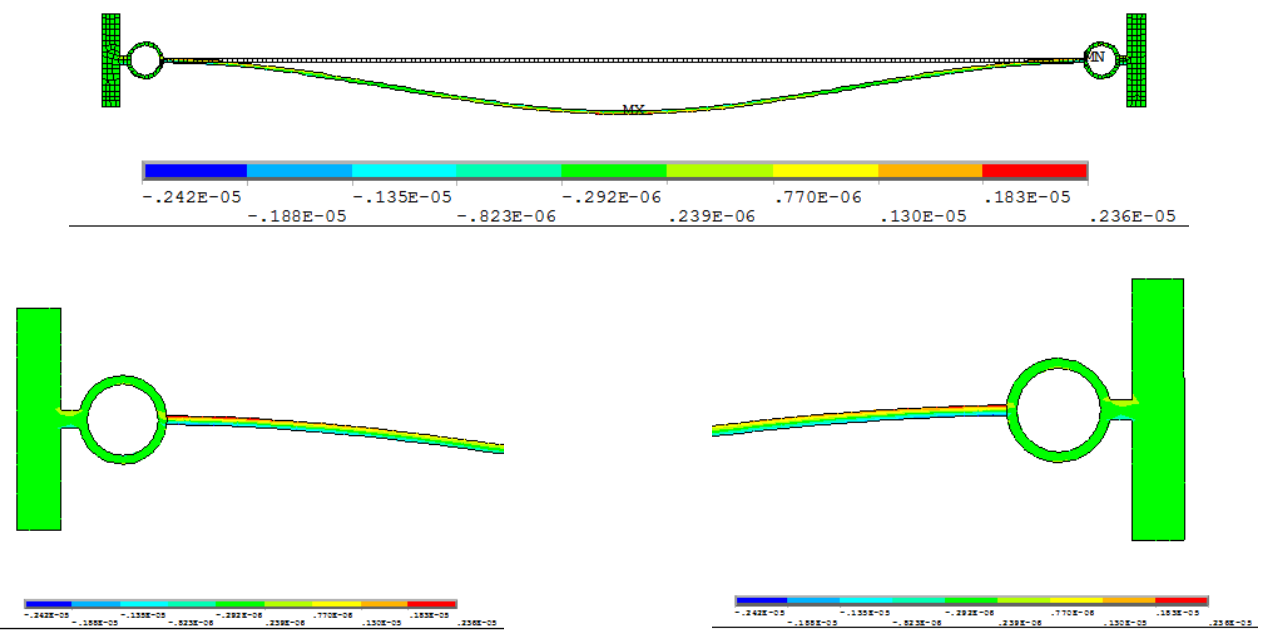

Fig.3 Result of simulation 


\section{Conclusion}

In view of the operation safety problem in arm of tower crane, a novel safe belts hanging protection device which has the characteristics of easily removed and high safety is proposed. Based on mechanical theory, constrains of rope diameter, fixed plate thickness, orifice cross section, the bolt size are discussed. However, the design of the proposed protection device is really an exercise in trade-offs. A parameter design approach is proposed in the system design. It is important that system controllability is checked before the design is concluded.

\section{Acknowledgement}

This work is supported by science and technology planning project of General Administration of Quality Supervision, Inspection and Quarantine of the People's Republic of China (No.2014QK260) and China State Administration of Work Safety Supervision (No. chongqing-0002-2015AQ).

\section{References}

[1] K. E. A. van de Sande, T. Gevers, and C. G. M. Snoek. Evaluating Color Descriptors for Object and Scene Recognition[J]. IEEE Trans. Pattern Anal. Mach. Intell., 32(2010)1582-1596.

[2]Xu Jinhai, Zhang Shikuo, Zhou Tong. Design and analysis of energy saving and environmental protection type mixing station. Construction Mechanization, 6(2014)97-98.

[3] Li Li, Niu Xiuyan, Yan Chunfeng. The Safe Tse of Tower Crane Bolt Connection[J]. Journal of Jilin Architecture and Civil Engineering Institute, 21(2010)45-47.

[4] Yu Lekang, Sun Zailu, Hang Shiwei.Security technology of Tower Crane[M].Beijing: Chinese Building Materials Industry Press, 2014.

[5] C. T. Liu, J. L. Kuo. Experimental investigation and 3-d modeling of linear variable-reluctance machines with magnetic flux decoupled windings[J]. IEEE Transactions on Magnetics, 30(1994)4737-4739.

[6] Wang Wenhao, Mao Xiaofei, Ye Xuehua. Stress Analysis of Standard Mast Joint of Tower Crane[J]. Mechanical Engineering \& Automation, 6(2013)23-25. 